NBER WORKING PAPER SERIES

\title{
LOCAL SOLUTIONS TO GLOBAL PROBLEMS: POLICY CHOICE AND REGULATORY JURISDICTION
}

\author{
James Bushnell \\ Carla Peterman \\ Catherine Wolfram \\ Working Paper 13472 \\ http://www.nber.org/papers/w13472 \\ NATIONAL BUREAU OF ECONOMIC RESEARCH \\ 1050 Massachusetts Avenue \\ Cambridge, MA 02138 \\ October 2007
}

We are grateful to Max Auffhammer, Dallas Burtraw, Alex Farrell, Larry Goulder and Dan Skopec for helpful discussions and comments. The views expressed herein are those of the author(s) and do not necessarily reflect the views of the National Bureau of Economic Research.

(C) 2007 by James Bushnell, Carla Peterman, and Catherine Wolfram. All rights reserved. Short sections of text, not to exceed two paragraphs, may be quoted without explicit permission provided that full credit, including $\odot$ notice, is given to the source. 
Local Solutions to Global Problems: Policy Choice and Regulatory Jurisdiction

James Bushnell, Carla Peterman, and Catherine Wolfram

NBER Working Paper No. 13472

October 2007

JEL No. Q48,Q54

\begin{abstract}
This paper considers the efficiency of various types of environmental regulations when they are applied locally to pollutants whose damages extend outside the jurisdiction of the local regulator. We draw on examples from state- and city-level efforts to address climate change by enacting policies to reduce greenhouse gases. While previous work has noted the possibility for leakage, whereby the polluting sources move outside the jurisdiction of the regulation in order to escape it, we note an additional problem when policies are targeted downstream at consumers of goods whose production creates pollution. Specifically, we show how consumer-based policies can be circumvented by a simple reshuffling of who is buying from whom. We argue that the leakage and reshuffling problems are most pronounced with more flexible or market-based regulations. We conclude that localities may have the most effect on global pollutants when they enact efficiency standards or targeted subsidies.

James Bushnell

University of California Energy Institute

2547 Channing Way

Berkeley, CA 94720

and NBER

bushnell@haas.berkeley.edu

Carla Peterman

UC, Berkeley

2547 Channing Way

Berkeley, CA 94720

cpeterman@berkeley.edu

Catherine Wolfram

Haas School of Business

University of California, Berkeley

Berkeley, CA 94720-1900

and NBER

wolfram@haas.berkeley.edu
\end{abstract}




\subsection{Introduction}

In this paper, we explore the intersection of two emerging trends in the environmental arena that are coming into increasing conflict with each other. On the one hand, there has been a movement toward more market-based regulations, which economists have long argued for on theoretical grounds. Market-based regulations such as cap-and-trade mechanisms can provide more flexibility for compliance, and thereby achieve environmental targets with greater efficiency and lower cost. They can also create stronger incentives for compliance and for innovation.

On the other hand, the trend toward liberalized regulatory tools has coincided with increased environmental activism on a local scale. This is particularly the case with climate change. Within the United States, a handful of states, impatient with what is perceived as inadequate Federal action, have adopted various forms of local controls designed to address climate change. Notably, states are acting alone even though the impacts, and sources, of the problem extend far beyond any local jurisdiction.

Local environmental action on climate change has not been limited to the state level. Many U.S. cities have adopted climate change policies (for example over 700 mayors have signed on to the U.S. Conference of Mayors Climate Protection Agreement). Indeed, the growing market for voluntary carbon offsets, purchased by individuals, can be viewed as the ultimate local action. Further, in the case of climate change, the global nature of the problem means that actions taken by individual countries can be subject to the same local problems as cities or states.

In this paper, we argue that the emergence of these two trends has become problematic where they overlap. While market-based environmental regulations hold great promise relative to more traditional regulatory tools, limiting their application to local jurisdictions can undermine their effectiveness. The very flexibility that makes 
market based regulations attractive can make them liable to circumvention if only applied locally.

Much of the problem stems from the ability of firms to source their production outside of the reach of the local regulation. In many cases this may involve the physical relocation of the economic activity. In other circumstances, it may involve simply a paper reshuffling of the matching between specific products and the consumers receiving those products. For example, we demonstrate how a market-based cap-and-trade policy for greenhouse gases, such as one proposed for California, could have very little effect on carbon emissions from the electricity sector if applied only to that state.

This raises the question of what small jurisdictions like California, Cambridge, MA or Berkeley, CA are trying to achieve with their greenhouse gas policies: Is the goal to truly reduce greenhouse gas emissions, and not just cause the sources to change location? Or is the goal to produce a regulatory policy that could be scaled up to a national level, and provide a framework for economically efficient reductions if the policy were more widely adopted? Just as states like California must consider both the direct and indirect impacts of its regulations, as well as its ability to influence its neighbors and Federal policy, individual nations must address the same issues on the international stage.

These issues are sometimes framed as a debate between the merits of a "narrow but deep” vs. "shallow but broad” sets of emissions reduction goals (see, e.g., Aldy, Barrett and Stavins, 2003). Some policies focus on an ambitious (e.g. deep) set of reductions applied to a small (e.g. narrow) set of jurisdictions. The Kyoto Protocol has been characterized as narrow but deep, and state- and city-level goals, which call for deeper reductions in much smaller jurisdictions, must be considered even more so.

The main criticism of narrow but deep strategies has been the potential for leakage, as industries migrate to locations outside of the regulatory regime. The proponents of the shallow but broad strategy argue that without widespread participation, the leakage issues 
will overwhelm the best efforts of the participating countries and eventually undermine efforts everywhere.

This paper highlights another way in which narrow but deep policies can be circumvented through a contractual reshuffling of who buys from whom. The problem is similar to an ineffective consumer boycott. Leakage is most relevant when the regulatory policies apply to the producer, while reshuffling is a concern when buyers are subject to regulations (i.e. downstream regulation). The difference between leakage and reshuffling is that the former involves a physical change in the location of the economic activity, while reshuffling simply changes the matching between specific sources and consumers. Therefore, while leakage can be costly for firms who have to relocate their production, with reshuffling, production does not change, and neither do costs.

Ironically, the tools that offer the best prospect for local regulators to make real progress toward an environmental goal may be those that are among the least attractive from an economic efficiency perspective for regulation on a large scale. In particular, targeted subsidies for "clean technologies," although vulnerable to political favoritism and limited in flexibility, can create a measurable impact on pollution. Therefore, although local subsidies for energy-efficiency, renewable electricity, and transportation bio-fuels constitute attempts to pick technology winners, they may be the only mechanisms that local jurisdictions, acting alone, have to impact climate change.

The remainder of this paper proceeds by stepping through three broad categories of regulatory tools: standards, subsidies for "clean” technologies and market-based policies. We describe the issues that arise in trying to apply these tools on a local scale. We draw on examples from state efforts to reduce greenhouse gas emissions, focusing particularly on the electricity industry. The electricity industry not only accounts for the most $\mathrm{CO} 2$ emissions of any single sector in the US economy, but it has also been the target of many of the early policy proposals to reduce greenhouse gas emissions. Although we categorize these policies, as for example, a "standard" or a "subsidy," in many cases 
policies can share attributes of more than one type of regulatory approach. The distinctions between these regulatory approaches are best thought of as falling along a continuum than a bright line.

\subsection{Environmental Regulatory Tools}

\subsection{Regulatory Standards}

The first class of regulatory tools we discuss is the regulatory standard. Regulatory standards, or command-and-control regulations, have at times been criticized by economists as an inflexible and inefficient approach to dealing with environmental problems. Under such an approach, a regulatory body determines a standard - such as a maximum limit on the emission of a pollutant or on the energy usage of an appliance and requires all sources (power plants, appliances, etc.) to individually comply with that standard. The standard could require adoption of a specific technology, such as selective catalytic reduction for NOx control in electricity plants, or specific gasoline formulations.

If a standard is enforced broadly, this approach is usually very effective at achieving the environmental goal. The main criticism has been that this environmental success can be much more costly to achieve than necessary, both in terms of the costs to the firms and also in terms of foregone consumer welfare of people who would otherwise consume a product that is banned by the regulatory standard. This is because all firms are required to meet the same standard. If there is heterogeneity across firms, for instance in the production processes they are using or in the vintage of their capital, it may be relatively inexpensive for some to achieve substantial emissions reductions, while for other firms any reduction in emissions will be cost prohibitive. In short, source specific standards do not recognize the potential differences in compliance costs across the regulated sources, and therefore cannot take advantage of these differences. The severity of this problem is obviously closely related to how significant those potential 
cost differences really are. Unfortunately, it is often difficult to know exactly how much costs may vary before the regulations are put into place.

It is important to recognize that, in addition to spurring the proliferation of mitigation technology, the application of environmental standards also influences industrial activity. The decision by firms to comply with an environmental standard is taken in the context of more general decisions about how much and where their product should be produced. A stronger standard will, at least weakly, reduce overall production and can spur production to relocate to regions where the standard does not apply or is not enforced.

For example, the enforcement of the U.S. Clean Air Act has stratified the country into areas of "attainment” and "non-attainment” of clean-air targets. In non-attainment areas, more stringent and costly emission standards apply. Research has demonstrated that industrial activity declines in non-attainment areas and is at least partially displaced by growth in attainment areas where regulation is less costly (see Greenstone 2002, and Becker and Henderson 2000).

When considering the migration of polluting sources away from areas of stringent regulation, it is critical to recognize the varying impacts of local pollution. Many of the CAA criteria pollutants cause damage close to where they are emitted, the classic example being ground-level ozone, which contributes to smog. Therefore the out migration of polluting sources is not necessarily a bad thing. Indeed it no doubt has contributed to the improvement in air quality in many areas of the United States. To the extent that the "growth" regions are less vulnerable to damage, or simply much less populated, this can be a net social gain (see Becker and Henderson 2000).

However, in some cases the out migration of polluting sources may not improve the local environment. This can be the case if the plants move "up-wind" of the region they are leaving, or if the region applying the standard is very small relative to the geographic scope of the environmental problem. Climate change represents the most 
extreme and challenging case. To a first order, the location of GHG emissions does not influence their impact on the climate. In effect, when it comes to climate change, everywhere is upwind.

The global public good aspect of the climate is therefore, one of the great challenges to formulating climate change policy (see Nordhaus 2007). To the extent that local regulations cause out-migration or "leakage" of regulated facilities, rather than a true reduction from local sources, the local environment does not improve. In addition to leakage, some regulatory standards may be achieved simply by reshuffling contractual relationships.

Standards Designed to Reduce Growth in GHG Emissions

Recent utility regulations in California provide a discouraging example of the reshuffling problem. California senate bill 1368 establishes a standard for purchases by “load-serving entities” (LSEs), the firms responsible for buying electricity for end-users in California, from "baseload" power plants. The law requires that new energy purchases and investments by California LSEs come exclusively from low-carbon power plants. ${ }^{1}$

In Bushnell, Peterman and Wolfram (2007) (hereafter BPW (2007)), we demonstrate that ample resources outside of California that are compliant with the standard already exist. California utilities can comply with the standard by buying from the existing low carbon sources, leaving the "dirty" sources to meet demand from other states (see BPW 2007). The California electricity context therefore demonstrates how a standard can be met on paper without any real impact on pollution. This is another

\footnotetext{
${ }^{1}$ Specifically, the law requires that power plants from whom these LSEs buy power under long-term contracts, invest in, or build themselves, must meet a standard that limits their emissions to be no greater than a current combined-cycle natural gas plant.
} 
important shortcoming to source-specific standards beyond the classic criticism that they ignore diversity in compliance costs.

In addition to limits on the carbon emission rate of electricity generation, a related "low carbon fuel standard" (LCFS) has been developed for transportation fuels. California's LCFS will require fuel providers to reduce carbon and other greenhouse gas emissions of transportation fuels by at least 10 percent by 2020. The expected flexibility of the LCFS allows fuel providers to exercise a myriad of options to reduce greenhouse gases including the blending of lower carbon fuels and purchasing credits.

Although California's LCFS proposal is the most advanced, similar standards have been proposed in the U.S. Congress, United Kingdom, British Columbia, Washington, Oregon, Arizona, New Mexico, Minnesota, Illinois, and the European Union. In practice, a LCFS is effectively a subsidy to bio-fuels, so we discuss it in more detail in the following section. One particular aspect of the LCFS is relevant to the current discussion. Specifically, by taking a lifecycle approach, the proposed standards attempt to differentiate between low and high-carbon bio-fuels, by tracking bio-fuel production up the supply chain. Ethanol produced from lower-carbon crops and farming methods would earn more credit under the California proposal. However, applying these standards locally raises similar problems to that of buying electricity from low-carbon power plants. If California requires its firms to buy clean ethanol, then firms in other states will buy the dirty ethanol forsaken by Californians. There would only be a net change in clean ethanol production if the amount of clean production everywhere is less than the requirements of California customers.

Local standards aimed at the carbon-content of energy sources are vulnerable to regional reallocation of those sources. By contrast, standards that have focused on a reduction of energy consumption promise to have more impact at the local level. Energy efficiency standards are another type of regulatory command-and-control that has been adopted to control GHG emissions. Efficiency standards can have more of a meaningful 
local effect if they apply to consumption choices that are inherently local - such as residential and commercial building and lighting standards - for which leakage is not a serious issue.

The impact of standards on more fungible consumer goods, such as appliances or vehicles, is more complex. If a jurisdiction is large enough, a local standard can force an industry past a tipping point beyond which it is easier to produce all goods, even those sold outside the regulated region, to comply with that local standard. The local standard, far from being bypassed, actually gets leveraged onto other regions. With other goods, the economics of production and customer demand may result in a mix of compliant and non-compliant products. To the extent this mix existed prior to the application of the local standard, the adoption of that standard could simply draw in the compliant products from other regions who substitute to non-compliant products.

\subsection{Promoting “Clean” Energy Sources}

In the policy arena, a popular alternative to limiting the use of "dirty” technologies through regulatory standards is the promotion of alternative, “clean” technologies. The promotion of such technologies can be accomplished through direct subsidies for the manufacture or installation of the technologies, through tax incentives, or through mandates that certain institutions buy a certain percentage of their consumption from clean sources. The political appeal of such an approach is obvious: instead of appearing to raise the cost of conventional energy sources, these tools appear to lower the cost of the alternatives.

Proposals for a low-carbon fuel standard (LCFS) for transportation fuels illustrate this point. As discussed above, a LCFS would require a reduction in the average carboncontent of transportation fuels. The focus is on the mix of transportation fuels sold, rather than a reduction in the consumption of transportation fuels. In this way, it is largely a 
subsidy for ethanol and other bio-fuels. ${ }^{2}$ Although encouraging a transition from petroleum based fuels to bio-fuels can reduce the GHG impact of each mile traveled, the production of bio-fuels themselves still create greenhouse gasses. Thus subsidizing a source that is less bad than the alternative is still promoting over-consumption of the bad.

Proponents of these policies often point to a variant of the "infant industries" argument. This hypothesis, often applied in the context of international trade, argues that certain technologies or industries can be very competitive with incumbent technologies if they could capture the necessary economies of scale or learning. The subsidies promoting these technologies thus speed up the development, moving the industry along the learning curve faster, or allowing it to grow to a minimum efficient scale more quickly. Once these technologies reap the benefits of such efficiencies, no further intervention is necessary. These new alternatives will, in theory, be preferred even if the environmental costs of the old technologies are not borne by the producers.

It is important to note that even the presence of a strong potential for learning or scale economies does not necessarily create a market failure. The key issue is whether those economies can be appropriated, through patents or a dominant position in the market, or whether there are significant knowledge "spillovers.” If a firm can profit from developing a new technology, there is a market incentive to innovate. If the innovations are easily copied by competitors, investment in research and development becomes a public good, thereby justifying public support.

There are several criticisms of such policies. First, although it is perhaps politically appealing to make clean technologies look cheaper, rather than make dirty sources seem more expensive, such an approach sends the wrong message to consumers. There are no additional costs associated with continued consumption from dirty sources. The opportunity for encouraging conservation in the obvious way, by making the

\footnotetext{
${ }^{2}$ See Holland, Knittel and Hughes (2007) for a detailed examination of California’s proposed LCFS policy.
} 
production more expensive, is therefore lost. In practice, the cost of the subsidies are often borne by other customers, so at least indirectly dirty consumption can be made more expensive.

A second, related criticism of "green" subsidies is that by drawing demand away from traditional sources, they will indirectly reduce the prices of the dirty product. From a consumer perspective this can sound appealing, but from the perspective of an environmental regulator, lower prices for dirty products are counter-productive. Even if consumption from the targeted product is discouraged within the region where the subsidies are applied, lower prices will encourage consumption elsewhere. ${ }^{3}$

Therefore, even the subsidies of alternative energy sources, when applied locally, are not immune to spillovers in other regions. In fact, the impact of a local regulation will come down to the relative price impacts of those subsidies on the "clean" and "dirty" technologies, and the elasticity of demand for those technologies in other regions. When adopted by small jurisdictions, these price impacts are likely to be small.

The choice of regulatory options, for a local regulator, therefore comes down in part to whether the price impacts of subsidies produce less damaging spillovers than the leakage and reshuffling effects of standards or market-based regulations. In most of the markets we discuss here, particularly electricity, the leakage and reshuffling problems are almost certainly more pronounced than any price impacts on coal or natural gas.

Perhaps the most poignant criticism of targeted subsidies is that they rely upon a very judicious regulatory process for them to be implemented efficiently. Even with very intelligent and dedicated regulators, the information requirements to pick the "right" technologies are daunting. The risk of large subsidies going to technologies that would not prove competitive under ideal regulations is very high. Politicians and regulators are

\footnotetext{
${ }^{3}$ This argument has been noted in the context of the adoption of bio-fuels to combat US oil dependence, but it is worth noting that the lowering of natural gas prices has also been cited as a benefit of aggressive adoption of renewables (see Wiser, Bolinger and St. Clair 2005).
} 
in effect placing large bets that the promised economies of scale and learning will in fact materialize. If these benefits do not appear, there are often calls for continued subsidies. There are many cases of "infant” industries that have never grown up.

There is no question that politics also plays an important role in the subsidies game. Many argue that the U.S. focus on corn-based ethanol is heavily influenced by the politics of the Midwestern farm-belt. Federal tax incentives provided for the purchase of hybrid-fuel cars were deliberately designed to favor producers who sell hybrids in smaller volumes. These producers also happened to be the U.S. auto manufacturers. Of course, this criticism could be leveled at just about any regulation or public policy. Because they often involve direct transfers of money to some parties, however, subsidies appear to be even more vulnerable to these pressures than other regulations. Further, once subsidy programs are set in place and are conferring direct benefits to specific groups, it can be politically difficult to take them away.

Despite all the potential faults of direct, targeted subsidies, they do feature one distinct advantage over the other policies discussed here: they are less vulnerable to leakage or other means of bypassing emissions regulations. They can therefore be more appealing to smaller jurisdictions, such as US cities or states, than other regulatory tools that can be more easily bypassed. While such policies may not be an appealing choice on a national or international scale, they may be the only means to meaningfully impact emissions on a more local level.

\section{Alternative Energy Policies for the Electricity Industry}

Regulators have adopted a wide variety of initiatives to encourage specific alternative energy technologies for producing electricity. For illustrative purposes, we will focus our discussion on two prominent programs that represent different implementation philosophies: state-level renewable portfolio standards and the California 
Solar Initiative. The two policies are very different in their approaches, but share the general feature that they focus on the inputs into the production of electricity, rather than the output of greenhouse gasses.

As of this writing, twenty-seven states and the District of Columbia have adopted renewable portfolio standards (see figure 1). While the details of the implementation vary, these share the common characteristic that they impose a requirement that electric utilities within the states meet a certain percentage of their demand with energy from renewable sources. Conceptually an RPS does not target a specific technology, but rather a class of technologies, for preferential treatment. ${ }^{4}$ The advantage over a more targeted subsidy is that these various renewable technologies compete against each other. In theory, the "best" (or lowest cost) choices amongst renewable options will come to dominate the portfolios of firms. Thus, for example, if solar photovoltaics (PVs) continue to be one of the most expensive renewable options, electric utilities are free to invest in other more economic choices. In this way, the RPS shares features of more market-based approaches to regulation.

The RPS policies also have their limitations. Because of their focus on the fuel inputs, rather than carbon output, firms do not have an incentive to develop alternative solutions to the emissions challenge, such as energy-efficiency, carbon sequestration, or nuclear power. Many believe that significant investment in some or all of these nonrenewable alternatives will be necessary to achieve long-term GHG reduction goals. Further, although there are aspects of inter-resource competition in the RPS, the playing field may not be completely level. For example, when accounting for the costs of various renewable technologies, it is not clear how the costs of new transmission, which will likely reach many billions of dollars, will be treated. Last, some renewable sources such as biomass, may have questionable GHG benefits.

\footnotetext{
${ }^{4}$ RPS policies in fourteen states do require some portion of the RPS to be met with a specific technology, but these amounts are small relative to the total RPS requirement.
} 
The RPS has been and will continue to be a strongly binding regulation that is dramatically changing the procurement practices of electric utilities. This is because the amount of renewable capacity necessary to meet states’ RPS obligations does not yet exist. Because little renewable capacity exists outside of California and Texas (see table 1), the option to comply by exporting dirty power and importing the renewable energy from other states is limited.

In contrast to the RPS, several States and cities have adopted policies to promote specific alternative energy sources. Perhaps the most ambitious of these in the U.S. is the California Solar Initiative (CSI). The initiative is a set of direct subsidies for property owners who install solar photovoltaic systems on their buildings. ${ }^{5}$ Over the next ten years, the program allocates up to $\$ 2.8$ billion, drawn from general electric rates, for these subsidies. The program represents a classic example of a targeted subsidy. Its proponents claim that an expansion of solar PVs in California will spur new efficiencies their design, production, and installation and will spur local economic investment in the industry. However, these benefits are far from guaranteed.

As critics of the program have pointed out, an injection of even several hundred million dollars per year into the worldwide solar PV market, estimated at over $\$ 5$ billion, while significant, would hardly constitute the dramatic, transformational, change in demand necessary to capture needed efficiencies. A program of this scale would likely ramp up production capacity of the existing technology, rather than spur needed innovation in new technologies. At current costs, current generation solar PV represents a curious technology to place a bet on. Even generous estimates indicate that solar PV installations cost about 30 cents/kWh, many multiples of the current costs of coal,

\footnotetext{
${ }^{5}$ The original form was adopted by the California Public Utilities Commission, and 2006 Senate Bill 1 extended the program to most municipal utilities. Interestingly the largest California municipal utility, LADWP is in effect exempted from these policies.
} 
natural-gas, or even wind-powered electricity generation. ${ }^{6}$ If the hoped for efficiency benefits of these subsidies do not materialize, the energy procured under this program could be four to five times more costly than other alternatives.

\subsection{Market-Based Environmental Regulations}

We next consider market-based regulatory approaches, which could include taxes on carbon emissions or programs through which the government limits carbon emissions by issuing permits that can be traded among polluters (so-called “cap-and-trade” policies). Rather than dictating the specific technology or fuel choice to be used in reducing emissions, these programs use price signals to provide incentives to firms to reduce emissions in the most cost-effective way possible.

Because of their inherent flexibility, these policies are attractive in circumstances in which they can be practically applied. They do not require a perfectly-informed regulator to come up with the optimal carbon-reducing strategy. Individual firms will in theory arrive at their least-cost method for reducing emissions because, under most circumstances, they have an incentive to do so. ${ }^{7}$ Regulators still play a central role in a market-based system - the parameters of the regulatory instruments will drive firms’ decisions - but their role is more limited than under other regulatory approaches.

\footnotetext{
${ }^{6}$ See Borenstein (2007). At the residential level, these costs are further subsidized by the practice of "net-metering." Generation from residential power sources can be used to offset not just the cost of utility electricity generation, but also the sunk costs of the network infrastructure such as transmission wires and other utility operations. This practice has been workable on a small scale, but may become unwieldy if extended to a large number of residences. The problem is that the other, non-solar residences have to pay relatively more for these infrastructure costs since they are spread over a smaller number of customers, in addition to funding the direct subsidies for the solar installation. ${ }^{7}$ There are cases where a firm's incentives may not be aligned strictly with minimizing its compliance costs. For example, a regulated firm may prefer options that can be added to its rate base (see Fowlie 2006).
} 
An emissions tax places an explicit charge on each unit of pollution produced by a firm, or individual. ${ }^{8}$ If a firm has options for reducing its emissions that are less expensive than the tax itself, it should adopt those options and reduce its emissions. Importantly, one of the options likely to be considered is simply consuming less of the input that is producing the pollution (e.g. fuel, fertilizer, chemicals). Thus taxes, in a relatively straightforward fashion can directly, and appropriately, impact both production and consumption choices in a market. The tax revenues can be applied to efforts to further reduce emissions or used to offset other taxes. In practice it is often the case that taxes are not directly applied to the pollutant, but rather indirectly at sources contributing to pollution, such as gasoline. These taxes may not have been imposed for the sake of environmental regulation, but do impact the behavior of firms and individuals, and therefore the environment, nonetheless.

There are two facets of emissions taxes that contribute to their perception as the intellectual playthings of ivory-tower economists, rather than practical tools for policymakers. First, they are viewed as extremely unpopular and therefore politically infeasible. Taxes in general are a hard sell, although "sin” taxes (applied to socially unappealing activities such as smoking and consuming alcohol) have often been the first recourse for policymakers that have been forced to raise revenue. It is important to stress also that these taxes need not even increase government revenues, but could be used to offset other taxes. However, critics point out that such a revenue neutral approach to new taxes would be rather novel in the history of government.

The second important concern with emissions taxes is that they do not guarantee that emissions will in fact be reduced. If consumers and firms decide that paying the tax is less costly, or more convenient, than reducing pollution, then the tax will raise revenues without actually changing behavior. More realistically, taxes may change behavior

\footnotetext{
${ }^{8}$ Nordhaus (2007) goes through many of the advantages of taxing carbon rather than setting quantity limits through something like a cap-and-trade policy.
} 
somewhat, but figuring out exactly how much is a complicated forecasting exercise. Environmental regulations are usually developed with a target in mind (e.g., ambient concentrations, source specific emission rates). Once that target is developed, regulators usually feel more comfortable implementing measures that they are confident will reach that target. ${ }^{9}$

Fortunately, even the regulation of emissions quantities can be achieved in a marketbased fashion. The cap-and-trade approach to emissions regulation is an example of a market-based regulation of quantities. A cap-and-trade system applies an overall regional limit to total emissions (the cap) and allows for flexibility as to which sources within that region actually emit. Emissions credits, totaling no more than the regional cap, are created and allocated to the regulated firms. In theory, firms that can cheaply reduce their emissions will sell credits to firms that find it very expensive to reduce (the trade). The net result is that the emissions target is achieved in a way that minimizes overall costs.

The concept of emissions credit trading has had a colorful history in the United States. Originally the concept was derided as the moral equivalent to selling "indulgences" for sins. The application of a cap-and-trade system for SO2, developed under the 1990 amendments to the Clean Air Act, has been widely viewed as successful (see, e.g., Stavins 1998 and Ellerman 2000). Since that time, emissions trading systems have become increasingly appealing to policymakers. One important practical advantage to these systems is that the regulatory burden can be smoothed through the allocation of the

\footnotetext{
${ }^{9}$ There is a rich literature in environmental economics, dating back to Weitzman (1974) on the proper use of "price" tools such as emissions taxes vs. "quantity" tools such as command and control regulations or emissions caps. The general idea is that taxes help to limit uncertainty over the costs of compliance while quantity regulations help to limit the uncertainty over how much pollution results. The choice is rarely strictly between one or the other. For example, an emissions limit is usually accompanied by a penalty for violating that limit. This penalty could be thought of as a tax on emissions above those imposed by the regulatory limit.
} 
credits. These allocations can be used to mitigate, or even co-opt, the opposition of firms who might be the most vulnerable to regulations of any kind.

It is important to recognize that cap and trade systems are not universally appropriate, or immune to criticism in practice. While the $\mathrm{SO} 2$ program has been viewed as a success, programs to trade certain smog-producing pollutants (NOx) in southern California and the eastern United States have run into a variety of problems.

For many pollutants, a key problem is coming up with a workable definition of the region over which the cap is to be applied. It is important to try to match the region being regulated to the region being impacted by the emissions. One shortcoming of most capand-trade systems is that they focus solely on how much pollution is being created and ignore the importance of where the pollution is coming from. For a more localized pollution problem, such as smog, this means that the capped region would ideally be relatively small. If the capped region is defined too broadly, there is a risk that emissions reductions will occur in regions where the pollution does little harm, and not where such reductions would have the most benefit. Thus the RECLAIM emissions credit program in southern California covered the LA basin but not the San Francisco Bay Area. Reductions in NOx in the Bay Area would have no benefit on smog conditions in LA.

Indeed, even the SO2 program has been criticized for ignoring the geographic importance of emissions. ${ }^{10}$ Regulators took the opposite of the RECLAIM approach to NOx trading in the eastern US, where NOx credits can be swapped amongst firms in nineteen states. Recent research has demonstrated that the bulk of the reductions in NOx emissions have been concentrated in southern states, even though most of health problems arise from emissions in the Midwest and Northeast (see Fowlie 2006).

\footnotetext{
${ }^{10}$ States in the northeast have complained that under the SO2 trading program, there has been relatively little reduction in $\mathrm{SO} 2$ emissions in states upwind of the eastern seaboard, which has borne the greatest impact of SO2 emissions.
} 
Although the nature of the pollutant may argue for a small trading region, small regions can lead to other problems. A small region will feature fewer firms that are subject to the regulation, and therefore less liquidity in emissions trades. Further a small region is more likely to be dominated by one or two large polluters who may enjoy market power either in the product they produce or in the pollution credits themselves. It appears that the RECLAIM program was plagued by both of these problems (see, e.g., Kolstad and Wolak, 2003).

A related problem arises when the definition of a region is too small to capture all of the relevant sources of pollution. This is the problem of leakage, where firms "reduce” their pollution in the regulated region simply by moving their facilities to an unregulated region. In the case of a localized pollutant such as NOx, this may not be a problem. It is likely efficient for smog-producing facilities to leave the LA basin for other areas where smog is a distant concern. In the case of GHG emissions, leakage is a major difficulty (see, e.g., Fowlie 2007). From a climate change perspective, California is equally vulnerable to GHG emissions in Nevada (or China) as it is to GHG emissions within its own borders.

One policy that could combat leakage is to focus regulation on a "consumption" standard rather than a "producer” standard. This means that, for purposes of tracking emissions, a firm is responsible for the emissions created by the plants it takes delivery of products from, no matter where those plants may be located. For example, an electricity firm in California that takes delivery of power generated by a plant in Utah will still be treated as "producing” the carbon from that plant in Utah. Similarly, firms burning ethanol in California would be responsible for the GHG emissions used in producing that ethanol, even if it was produced in Iowa. Such an approach requires potentially much more sophisticated monitoring of emissions activities, as the regulator is trying to track emissions all the way up the supply chain and far beyond its normal regulatory jurisdiction. There are also questions about the legality of such an approach for 
individual states. ${ }^{11}$ Assuming such tracking can be achieved, and the legal obstacles overcome, this approach can go a long way to preventing the perverse effects of leakage under the right circumstances.

Under some circumstances, however, a consumption-based application of capand-trade can fall victim to a comparable problem, the reshuffling of production. This is a problem, like leakage, that can arise when the area being regulated is much smaller than the area from which troublesome pollution can be produced. Although the regulator can force its local firms to buy “clean” products, it can’t keep firms in other states from buying the "dirty" products that the firms in the regulated states used to buy. If there is already substantial clean production capacity in neighboring regions, the regulation can result in the local firms simply swapping suppliers with their brethren in other states. For example, there is both clean (low-carbon) and dirty (high-carbon) ethanol produced in the U.S. today.

The problem is similar to the conditions that limit the effectiveness of consumer boycotts. Although a percentage of motivated customers stop buying from the boycotted source (e.g. diamonds thought to support "blood” regimes), there will be no net impact on sales or prices if there are enough other price-sensitive customers who are indifferent to the cause of the boycott and willing to shift over to the boycotted producers. As soon as prices from the boycotted sources fall because of the boycott, other customers shift over and prices rise again.

As we describe below, the leakage and reshuffling problems are of more than academic concern when it comes to local GHG policies. If States act unilaterally, without the participation of others in their regions, these problems could overwhelm any meaningful impact of the regulations.

\footnotetext{
${ }^{11}$ For example, some states have claimed that California's attempt to regulate the purchases of firms within its borders of products produced outside its borders violates the commerce clause of the constitution (see, e.g., Potts, 2006).
} 
State-level cap-and-trade proposals in electricity

There are two possible approaches to measuring the amount of emissions from the electricity industry: a consumption- or load-based measure and a production- or sourcebased measure. A source-based measure would regulate GHG gasses emitted only from plants physically located within the regulating region.

Such an approach though can be problematic for states located in large regional electricity markets. For example, a substantial fraction of California's electricity and a majority of the GHG emissions, come from plants outside of California. ${ }^{12}$ There is a significant risk that a source-based standard could be circumvented by simply increasing net imports from outside of the regulating states. Absent additional limitations, these imports would count as perfectly “clean” under a source-based standard.

The Regional Greenhouse Gas Initiative (RGGI), an effort of ten northeastern and mid-Atlantic states, employs such a source-based standard. It will be the first U.S. mandatory cap-and-trade program to control carbon dioxide emissions. Unlike California, the RGGI program will only regulate the electric sector. The initiative will stabilize carbon dioxide emissions at participating power plants to current levels through 2014 and then reduce emissions by 10 percent in 2019 .

Concern over emissions leakage has been raised with RGGI’s source-based system since some of the states participate in markets with generators outside of the capand-trade program. Debate persists regarding the extent to which such emissions leakage will occur, particularly since the magnitude will be affected by location-specific factors

\footnotetext{
12 The accounting of production is complicated somewhat by the fact that there is coal capacity owned by (or contracted to) California LSEs that is located outside of California but connected in such a way that, electrically, it is treated as within California. The CEC attributes over twenty-eight TWh of electricity generation to plants that fall in this category.
} 
and allowance prices. Modeling projections however estimate potential emissions leakage of eighteen to 27 percent through $2015 .^{13}$

The California policies most relevant to the discussion of market-based regulations are those that could emanate from the process initiated by California Assembly Bill 32 (AB 32). The bill itself does not establish specific policies, but rather articulates an overall goal of reducing California’s GHG emissions to 1990 levels by 2020 with a scope that extends well beyond the electricity industry to include most major sources of GHG emissions. The exact methods for achieving the goals articulated in the bill are to be determined by a process that is currently ongoing. Market-based regulatory tools, such as a cap-and-trade program, have been widely discussed but are also somewhat controversial.

Although several industries may be included within the California cap-and-trade regime, the electricity industry has received the most initial focus. Currently the leading options for a cap-and-trade system in California are the consumer (or load-based) approach and a first-seller approach. The first seller is a hybrid approach that is effectively source-based for plants within California and load-based for imported power. ${ }^{14}$ Although these two approaches treat sources inside of California differently, their treatment of imports from outside of California is very similar. The motivation for both options is a desire to reduce emissions from plants that are physically located outside of California, but sell to California consumers. Thus both systems regulate the downstream "importer" of power in an attempt to indirectly influence the outside sources.

\footnotetext{
${ }^{13}$ RGGI Emissions Leakage Multi-State Staff Working Group (March 2007). Potential Emissions Leakage and the Regional Greenhouse Gas Initiative (RGGI): Evaluating Market Dynamics, Monitoring Options, and Possible Mitigation Mechanisms. p.9.

${ }^{14}$ The Market Advisory Committee (MAC) an expert panel formed by the California EPA to study the implementation of AB 32 via cap-and-trade has recommended the firstseller approach (see MAC, 2007). See Bushnell (2007) for a more detailed discussion of the differences between first-seller and load-based approaches.
} 
While this approach may seem more likely to constrain imports than a pure source-based approach, it is vulnerable to a reshuffling of transactions. Consumers inside California can reduce their purchases from dirty plants and increase their purchases from existing clean ones, and firms outside of California could do the reverse.

To assess the plausibility of such an outcome, we examine the mix of generation available in the western electricity market. Table 2 shows the amount of energy produced in 2004 from each major fuel source in each sub-region of the western market. As is evident from this table, the amount of energy from zero-carbon sources, hydro and nuclear, is substantial. Also note that California has a relatively clean fuel mix (at least with regards to CO2), with large amounts of nuclear and hydro production and comparatively little coal production. To examine whether there is enough low-carbon capacity to meet California's AB 32 goals for electricity, we use a projection of California's 2020 electricity demand of about 341 TWh. $^{15}$ The CO2 emissions created to serve California demand in 1990 was approximately eighty-two million metric tons (MMT).

Figure 2 plots the cumulative $\mathrm{CO} 2$ emissions from power plants in the west in 2004 against the cumulative TWh of electricity produced by these plants, where the TWh are assumed to come from the lowest carbon sources first. For example, the function is equal to zero for the first 264 TWh of output because zero carbon sources produced 264 TWh of output in 2004. The horizontal line in figure 2 is drawn at the emissions level that California would need to achieve to meet the AB 32 standard (the 1990 level of 82.0 MMT) and the vertical line is drawn at the projected 2020 demand (341 TWh). The function crosses the vertical line before it crosses the horizontal line, suggesting that California could procure power in the western markets from existing sources without exceeding 1990 carbon emissions levels. This implies that even a load-based standard for

\footnotetext{
15 This number is comparable to the CEC's forecast of 340 TWh. For details see BPW (2007).
} 
California is at serious risk of circumvention through a swapping of energy sources amongst the western states.

This analysis reflects many important underlying assumptions about the willingness and ability of western electricity firms to trade their electricity. It is intended as an illustrative calculation to indicate the potential severity of the problem, rather than a forecast of what is likely to happen. That said, BPW (2007) consider several of the most likely impediments to a complete reshuffling of energy sources in a relatively straightforward way, and they do not change the overall conclusion that California is not a large enough player in the western electricity market to cause substantive change with a cap-and-trade policy.

The reshuffling in the electricity sector could impact the effectiveness of AB 32 in other sectors. If the cap-and-trade system allows trading across sectors, than electric companies could sell any excess allowances they create by reshuffling. Firms in other sectors could purchase the allowances created by reshuffling instead of actually reducing the carbon emissions from their production processes. This would limit the ability of a cap-and-trade system to reduce emissions in other sectors of the economy.

\section{Beyond Local Regulation}

The designers of both RGGI's and California's cap-and-trade policies recognize the challenges of implementing regulations on a less-than national scale. Various administrative rules relating to the accounting of emissions from "outside" the regulated region could reduce, or even eliminate, the incentives to reshuffle purchases. Most solutions involve fixing a default emissions value for imported power that can only be changed if the importer switches to a new facility, rather than an existing one. ${ }^{16}$ These

\footnotetext{
${ }^{16}$ For example, power purchases could be tied to a historic reference year, rather than actual current purchases. Thus a firm that bought power from a coal plant in 2000, for
} 
rules dilute the incentives of firms located outside the region to actually reduce emissions. They also blunt the accuracy of emissions measurement and could also draw legal challenges.

A far better outcome for the fate of a cap-and-trade program would be the expansion of its jurisdiction. At the end of February 2007, California Governor Schwarzenegger together with the Governors from Arizona, New Mexico, Oregon and Washington, announced a plan to do just that. The Governors outlined plans to establish a regional cap within six months and to set up a regional cap-and-trade system within eighteen months (see Eilperin, 2007). ${ }^{17}$ In view of this announcement, BPW (2007) examined a policy that would include the five states party to the agreement.

We find that a source-based standard would likely help to induce (or reinforce) a decision to retire a few coal plants by 2020. The key question though, is what kind of capacity would replace the production of those plants, and also generate the additional energy required to meet load growth in this region? The problem again with a sourcebased standard is that this additional production could be met from new facilities located outside of the five-state block. If the new plants are coal-fired, little overall benefit to the GHG problem is achieved.

Under a load-based standard, the imports would, in theory, be judged based upon the carbon content of their sources. We must now consider two further relevant facts in this analysis: the addition of sixty-five to seventy-five new TWh of renewable energy

example, would be responsible for the future emissions from that same plant, whether or not it continues to buy power from it. For more discussion, see Bushnell (2007). ${ }^{17}$ Carbon growth between 1990 and 2004 varied considerably state to state. States in the Pacific Northwest showed the highest proportional increases as a high fraction of their capacity installed by 1990 was hydro or nuclear plants, which are zero carbon sources. In terms of raw tonnage of carbon emissions, however, Arizona stands out as the state with the largest increase since 1990 (and therefore the farthest away from a target of reducing to 1990 levels). Arizona generation accounts for roughly half of the forty-two MMT increase in the five states since 1990 . 
under the various RPS in these five states, and the presence of roughly seventy TWh of hydro energy in neighboring regions of the WECC, including Canada. The combined 135-145 TWh of zero-carbon energy sources would be nearly sufficient to meet the emissions standard at the lower end of our load-growth projections, and the standard could be met if there is sufficient new zero-carbon generation added outside the five states. There are several reasons to believe that not all of this additional hydro energy would be available for reshuffling. A more realistic scenario is to assume that load growth is met with combined-cycle natural gas plants, which have CO2 emissions much lower than coal plants, but significantly above the zero-carbon nuclear, hydro, and renewable energy sources.

Following this alternative assumption, BPW find that these five states would have to abandon all the coal plants from which they currently consume energy, and instead buy power from new combined-cycle gas plants to meet 1990 CO2 targets if demand growth were at the low end of estimates. This is a significant investment in new gas plants, but hardly transformational, considering that a similar amount of combined-cycle gas capacity came online in the western US between 1999 and $2005 .^{18}$

In sum, as with a California-only policy, the BPW analysis suggests that even if carbon limitations are expanded to cover Arizona, New Mexico, Oregon and Washington, the biggest single driver towards less carbon-intensive electricity generation is likely to be the renewable portfolio standards. This is an example of an important issue in regulatory policy design, as often several different regulatory instruments are applied simultaneously. We take this topic up in the next section.

\footnotetext{
${ }^{18}$ Of course, a large expansion of natural gas-fired generation could have significant impacts on the market for natural gas in the West.
} 


\subsection{The Interaction of Regulatory Options}

Often, debates over the choice of the appropriate regulatory instrument fail to take into account the fact that any regulation will likely coexist with a host of other regulations that can impact the problem of interest. This is a particularly relevant issue when discussing market-based environmental regulations. The key advantage of market-based mechanisms is that they afford the regulated industry more flexibility as to how, and even how much, to comply. When the market-based mechanism is overlaid onto a series of other regulations, however, this flexibility can be greatly reduced. Nowhere is this truer than in the electricity industry, with its history of both strong economic and environmental regulation.

The limitations of overlapping regulation can have both positive and negative impacts. Research has shown that the economic regulation of firms, rather than a motivation to minimize costs, can drive their choice of compliance option under a capand-trade system (see Fowlie, 2006). This can, for example, lead to investments in capital intensive technologies being made by firms with the most favorable regulatory treatment, rather than those with the lowest cost.

On the other hand, when the market-based regulation is applied only locally, traditional regulatory instruments can limit the leakage and reshuffling problems that would otherwise arise. Indeed, regulators in both California and the RGGI states have expressed a commitment to using energy efficiency standards and to promoting alternative energy while developing a cap-and-trade system. Both regions are relying upon these other measures, in part, to limit the problems of a localized cap-and-trade market. $^{19}$

19 RGGI Emissions Leakage Multi-State Staff Working Group (March 2007). 
Yet these measures, which include aggressive commitments to renewable energy and to energy efficiency, as well as direct oversight of the procurement decisions of regulated utilities in their regions, will no doubt limit the impact of the cap-and-trade program. California’s electricity industry may be the most extreme case, with regulations of many flavors directed at reducing GHG. In addition to funding for energy efficiency and a RPS target of 20 percent of energy consumed by 2010, there are also explicit penalties and laws aimed at preventing investment in new coal-plants. ${ }^{20}$ Before energy efficiency targets are considered, the RPS alone should account for approximately half of the growth in demand for electricity in California between now and 2020. When expected energy efficiency is accounted for, California's RPS and energy efficiency programs will likely meet almost 95 percent of load growth leaving compliance with AB 32 down to reducing current emissions to 1990 levels. ${ }^{21}$ If California pursues some of the more aggressive proposed policies, (increasing RPS to 33 percent increasing energy efficiency, demand response, and PV), then these programs alone will enable California to reach its 1990 emissions levels and be in compliance with AB32, without engaging in cap and trade. $^{22}$

Potential Emissions Leakage and the Regional Greenhouse Gas Initiative (RGGI): Evaluating Market Dynamics, Monitoring Options, and Possible Mitigation Mechanisms. p.26-39.

${ }^{20}$ Only California's investor-owned-utilities (IOUs), representing approximately 70 percent of state load, are required by law to increase renewable generation to 20 percent of load. Based on publicly-owned-utilities (POU) renewable targets the California Energy Commission projects that POUs will meet 10 percent of their load by 2013 with renewable energy (CEC, 2007a, p.33).

${ }^{21}$ The California Energy Commission projects 2020 energy efficiency based upon the IOUs long-term procurement plans for the years 2009 through 2016 and POU program expectations (CEC, 2007a).

22 The California Energy Commission's Scenario 5A, "High Energy Efficiency and Renewables in CA only”, which includes such aggressive scenarios predicts 2020 carbon emissions to be close to 1990 carbon levels (CEC, 2007b, p.130). 
A similar trend can be observed nationwide. Existing state RPS programs are projected to meet approximately 60 percent of their state load growth between now and 2020. Congress is currently debating a national RPS and targets as high as 20 percent renewable generation by 2020 have been written into bills. Given current forecasts of load growth, renewable supplies could meet all new demand. If such a bill passed it would reduce the electric sector's compliance flexibility under any national GHG capand-trade system. ${ }^{23}$

\subsection{Summary}

In this paper, we have discussed the confluence of two recent trends: the growth in popularity of market-based environmental regulations and the increase in regulatory actions taken at a local level. We have pointed out how these trends can conflict with each other. The geographic reach of the regulator is an important consideration when determining the most effective form of environmental regulation. Market-based regulations, such as cap-and-trade, can be problematic for regulators with limited geographic reach. Despite this fact, greenhouse gas policies in the US are currently moving forward on a local basis, and cap-and-trade is an important element of these plans. There is a significant risk that the limited reach of these programs could lead them to be undermined either through the exodus of physical plants to unregulated regions or through a reshuffling of deliveries from sources outside the regulated area. In electricity markets, shipments are relatively low-cost and difficult to track to specific ultimate sources. The risk of regional markets adjusting to new carbon regulations in their midst

\footnotetext{
${ }^{23}$ Six national cap and trade bills are currently under consideration in the U.S. Congress. These bills on average target 1990 emissions levels in 2020. See Larsen (2007) for a comparative analysis.
} 
by a simple realignment of supply, rather than absolute reduction in emissions, is therefore relatively high.

Less flexible regulatory mechanisms, such as mandates or subsidies for "clean" alternative energy sources or energy efficiency standards, although less efficient when applied on a large scale, may be the only kinds of regulations that can produce meaningful results on a local level. In fact, the trade-offs are subtle. Even efforts that are effective in lowering local consumption from polluting sources can be diluted if they result in lower prices and hence increased consumption from those dirty sources elsewhere. In order to choose the policy with the lowest chance of spillovers to unregulated jurisdictions, a regulator is faced with evaluating whether the price impacts of subsidies produce fewer spillovers than the leakage and reshuffling effects of standards or market-based regulations. In most of the markets we discuss here, particularly electricity, the leakage and reshuffling problems are almost certainly more pronounced than any price impacts on fossil fuels.

These results highlight an important question. What are local regulators actually trying to achieve with their GHG emissions policies? Are the goals truly limited to forcing down the carbon footprint from activities within their jurisdiction? If so, one must keep in mind that the net carbon reductions from the policies proposed by a locality as large as California, assuming it achieves all its goals without circumvention, would amount to less than 200 MMTCE economy-wide, while China's emissions are forecasted to rise by several thousand MMTCE by 2015 (see Auffhammer and Carson, 2006).

Given this fact, it becomes clear that the local initiatives are largely symbolic unless they facilitate change beyond their local regions. It is useful to consider the policies that are most likely to have broader impacts, either by making it easier for other jurisdictions to adopt effective GHG regulations or by influencing the set of technologies that are available to reduce emissions. Here, it is useful to consider how generally applicable either the regulatory or technological lessons are. 
For all of the reasons laid out in the paper, it seems likely that the experiences with local regulations are unlikely to have much bearing on their effectiveness at a broader level. For example, while a California cap-and-trade policy for the electricity industry may be easily undermined by reshuffling and leakage, these issues are much less likely to be a problem on a national level. (Electricity is not a globally traded commodity.) Given political realities, though, an ineffectual California policy may make it less likely that a federal cap-and-trade policy will be adopted, even if the problems California experiences are unlikely to be replicated for a broader scale policy. On the other hand, if local policies lead to what are effectively demonstration projects of various technologies, their successes or failures will be important first steps in adopting effective low-carbon technologies on a more global scale. 


\section{References}

Aldy, Joseph E., Scott Barrett, and Robert N. Stavins. 2003.Thirteen plus One: A Comparison of Global Climate Policy Architectures. Climate Policy. 3: 373-397.

Auffhammer, Maximilian, and Richard T. Carson. 2006. Forecasting the Path of China's CO2 Emissions: Offsetting Kyoto - and then Some. UC Berkeley, Department of Agricultural and Resource Economics working paper.

Becker, Randy, and Vernon Henderson. 2000. Effects of Air Quality Regulations on Polluting Industries. The Journal of Political Economy, 108 (2): 379-421.

Borenstein, Severin. 2007. Electricity Rate Structure and the Economics of Solar Power. Center for the Study of Energy Markets Working Paper 172. University of California Energy Institute.

Bushnell, James. 2007. The Implementation of California AB 32 and its Impact on Wholesale Electricity Markets. Center for the Study of Energy Markets Working Paper 170. University of California Energy Institute.

Bushnell, James, Carla Peterman and Catherine Wolfram. 2007. California's Greenhouse Gas Policies: How Do They Add Up? UC Energy Institute working paper.

California Energy Commission. 2007a. Scenario Analyses of California's Electricity System: Preliminary Results for the 2007 Integrated Energy Policy Report. CEC-2002007-010-SD.

California Energy Commission. 2007b. Scenario Analyses of California's Electricity System: Preliminary Results for the 2007 Integrated Energy Policy Report. Appendices. CEC-200-2007-010-SD-AP.

California Energy Markets. 2007. Southwest Utilities Undaunted by CPUC’s New GHG Contract Policy. January 26.

Eilperin, Juliet. 2007. Western States Agree to Cut Greenhouse Gases. Washington Post, February 27.

Ellerman, Denny, et al. 2000. Markets for Clean Air. Cambridge: Cambridge University Press.

Fowlie, Meredith L. 2007. Incomplete Environmental Regulation and Leakage in Electricity Markets. University of Michigan working paper.

. 2006. Emissions Trading, Electricity Industry Restructuring, and Investment in Pollution Abatement. University of Michigan working paper. 
Greenstone, Michael. 2002. The Impacts of Environmental Regulations on Industrial Activity: Evidence from the 1970 and 1977 Clean Air Act Amendments and the Census of Manufactures. Journal of Political Economy. 110(6): 1175-1219.

Holland, Stephen, Christopher Knittel and Jonathan Hughes. 2007. Greenhouse Gas Reductions under Low Carbon Fuel Standards? Center for the Study of Energy Markets Working Paper 167. University of California Energy Institute.

Kolstad, Jonathan, and Frank Wolak. 2003. Using Environmental Emissions Permit Prices to Raise Electricity Prices: Evidence from the California Electricity Market. Stanford University working paper.

Larsen, John. 2007. Comparison of Economy-wide Climate Change Proposals in the $110^{\text {th }}$ Congress, 1990-2050. World Resources Institute. (last updated May 10, 2007).

Market Advisory Committee. 2007. Recommendations for Designing a Greenhouse Gas Cap-and-Trade System for California.

http://www.climatechange.ca.gov/documents/2007-06-29_MAC_FINAL_REPORT.PDF

Nordhaus, William D. 2007. To Tax or Not to Tax: Alternative Approaches to Slowing Global Warming. Review of Environmental Economics and Policy. 1(1): 26-44.

Potts, Brian H. 2006. Regulating Greenhouse Gas Leakage: How California Can Evade the Impending Constitutional Attacks. Electricity Journal. 19(5): 43-53.

RGGI Emissions Leakage Multi-State Staff Working Group. 2007. Potential Emissions Leakage and the Regional Greenhouse Gas Initiative (RGGI): Evaluating Market Dynamics, Monitoring Options, and Possible Mitigation Mechanisms.

Stavins, Robert N. 1998. What Can We Learn from the Grand Policy Experiment? Lessons from SO2 Allowance Trading. Journal of Economic Perspectives. 12(3): 69-88.

Weitzman, Martin. 1974. Prices versus Quantities. Review of Economic Studies. 61(4): 477-491.

Wiser, Ryan, Mark Bolinger, and Matt St. Clair. 2005. Easing the Natural Gas Crisis: Reducing Natural Gas Prices through Increased Deployment of Renewable Energy and Energy Efficiency. Lawrence Berkeley National Laboratory working paper (LBNL56756). http://eetd.lbl.gov/EA/EMP/reports/56756.pdf. 
FIGURE 1: STATE-LEVEL RENEWABLE PORTFOLIO STANDARDS

FOR ELECTRICITY CONSUMPTION

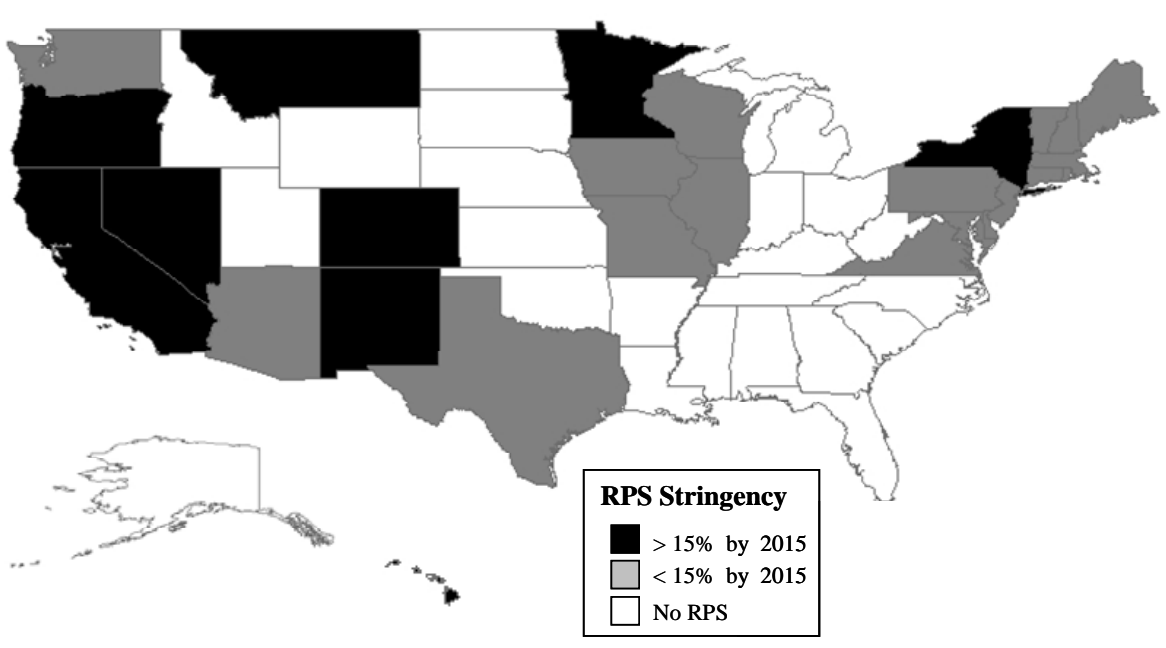




\section{FIGURE 2: ELECTRICITY SUPPLY AND CARBON LIMITS UNDER CALIFORNIA CAP-AND-TRADE}

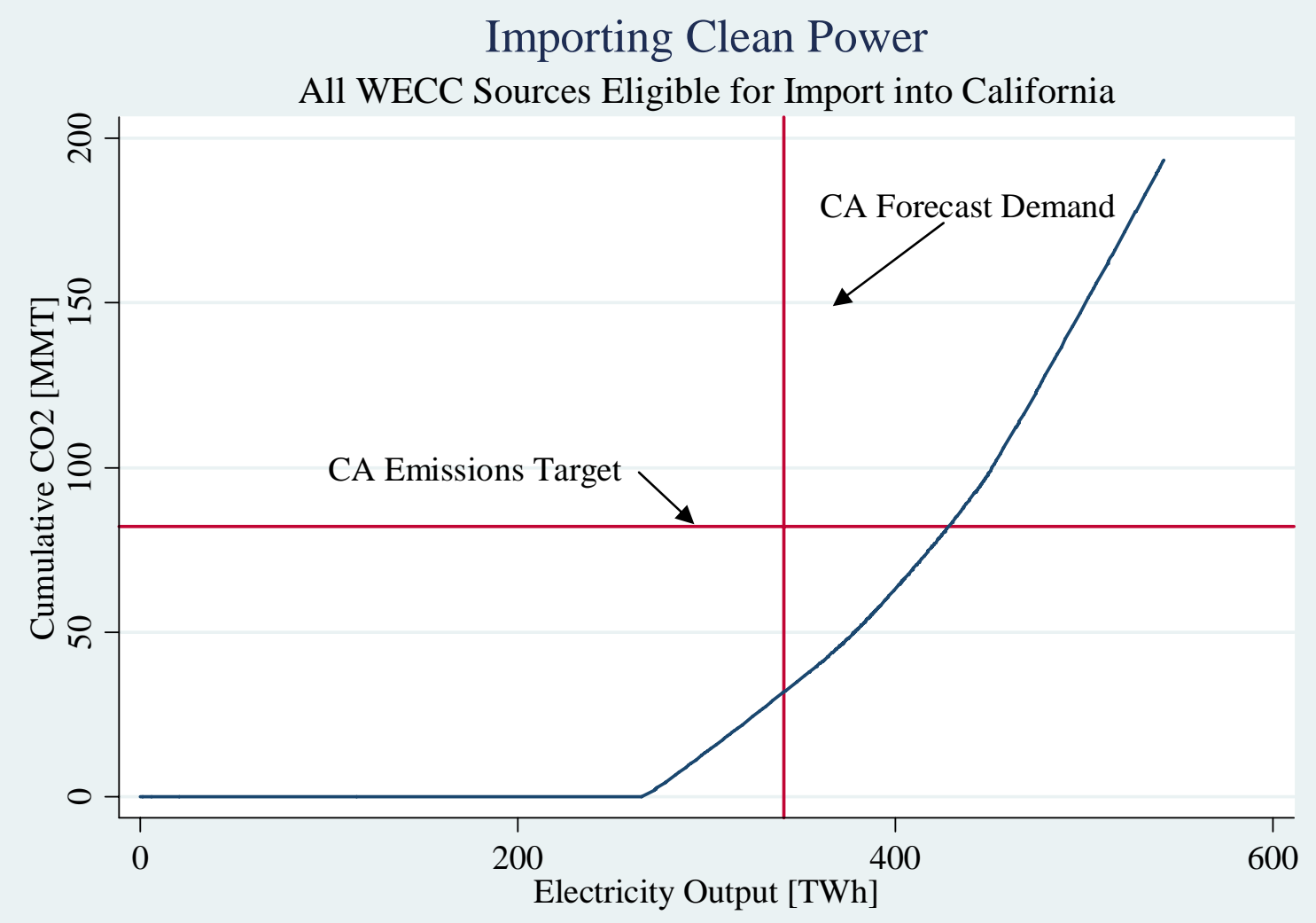

Note: The blue line traces cumulative CO2 emissions in 2004 as a function of cumulative 2004 electricity output from power plants in the WECC. 
Table 1: Renewable Supply in the U.S.

\begin{tabular}{|l|r|r|}
\hline & \multicolumn{2}{|c|}{ 2005 Renewable Supply } \\
\hline NERC region & \multicolumn{1}{|c|}{ TWh } & $\begin{array}{c}\text { \% of state } \\
\text { load }\end{array}$ \\
\hline ASCC & 0.0 & $0.2 \%$ \\
\hline FRCC & 5.8 & $2.6 \%$ \\
\hline HICC & 0.7 & $6.8 \%$ \\
\hline MRO & 5.8 & $2.6 \%$ \\
\hline NPCC & 12.3 & $4.4 \%$ \\
\hline RFC & 8.9 & $1.2 \%$ \\
\hline SERC & 21.6 & $1.9 \%$ \\
\hline SPP & 1.2 & $1.3 \%$ \\
\hline TRE & 4.6 & $1.4 \%$ \\
\hline WECC & 31.2 & $5.0 \%$ \\
\hline Total & 92.0 & \\
\hline
\end{tabular}

Sources: 2005 renewable supply: Electric Power Monthly, March 2006, Table 1.14B 2005 state load: Electric Power Annual 2005 - State Data Tables http://www.eia.doe.gov/cneaf/electricity/epa/epa_sprdshts.html 
Table 2: Energy Produced in 2004 by Major Fuel Source and Sub-Region (TWh)

\begin{tabular}{|c|c|c|c|c|c|c|}
\hline & California & AZ-NM & OR-WA & Rest of & Total & $\begin{array}{c}\text { \% Total } \\
\text { WECCC }\end{array}$ \\
\hline Large Hydro & 29.6 & 6.9 & 101.5 & 17.5 & 155.5 & $23 \%$ \\
\hline Nuclear & 30.3 & 28.1 & 9.0 & 0 & 67.4 & $10 \%$ \\
\hline Renewables & 28.5 & 1.0 & 5.1 & 6.1 & 40.7 & $6 \%$ \\
\hline Natural Gas & 96.2 & 32.4 & 22.5 & 36.9 & 188 & $27 \%$ \\
\hline Oil & 3.4 & $<.1$ & .3 & .2 & 3.9 & $1 \%$ \\
\hline Coal & 3.0 & 65.8 & 14.0 & 146.2 & 229 & $33 \%$ \\
\hline & 191.0 & 134.3 & 152.4 & 206.9 & 684.6 & \\
\hline
\end{tabular}

Source: U.S. Energy Information Adminstration (2004). EIA-906 and EIA-860 databases. 